\title{
Responsibilities, Strategies, and Practice Factors in Clinical Cost Conversations: a US Physician Survey
}

\author{
Rahma Warsame, $M D^{1,2}$, Lindsay Riordan, $B A^{3}$, Sarah Jenkins, $M A^{4}$, \\ Kandace Lackore, $B A^{4}$, Joel Pacyna, $M A^{4,5}$, Ryan Antiel, MD, MSME' \\ Timothy Beebe, PhD, MA , Mark Liebow, MD, MPH ${ }^{5,8}$, Bjorg Thorsteinsdottir, MD ${ }^{2,5,9}$, \\ Michael Grover, DO ${ }^{10}$, Matthew Wynia, MD, MPH ${ }^{17,12}$, \\ Susan Dorr Goold, MD, MHSA, MA ${ }^{13,14}$, Matthew DeCamp, MD, PhD 11,12, \\ Marion Danis, $M D^{15}$, and Jon Tilburt, $M D^{2,4,5,8}$
}

'Division of Hematology, Mayo Clinic, Rochester, MN, USA; ${ }^{2}$ Mayo Clinic Robert D. and Patricia E. Kern Center for the Science of Health Care Delivery, Mayo Clinic, Rochester, MN, USA; ${ }^{3}$ Mayo Clinic Alix School of Medicine, Rochester, MN, USA; ${ }^{4}$ Department of Health Sciences Research, Mayo Clinic, Rochester, MN, USA; ${ }^{5}$ Biomedical Ethics Research Program, Mayo Clinic, Rochester, MN, USA; ${ }^{6}$ Division of Pediatric Surgery, St. Louis Children's Hospital and Washington University School of Medicine, St. Louis, MO, USA; 'Division of Health Policy and Management, School of Public Health, University of Minnesota, Minneapolis, MN, USA; ${ }^{8}$ Division of General Internal Medicine, Mayo Clinic, Rochester, MN, USA; ${ }^{9}$ Division of Community Internal Medicine, Mayo Clinic, Rochester, MN, USA; ${ }^{10}$ Department of Family Medicine, Mayo Clinic, Scottsdale, AZ, USA; " 1 Center for Bioethics and Humanities, University of Colorado, Aurora, CO, USA; ${ }^{12}$ Division of General Internal Medicine, University of Colorado School of Medicine, Denver, CO, USA; ${ }^{13}$ Department of Internal Medicine, University of Michigan, Ann Arbor, MI, USA; ${ }^{14}$ School of Public Health, University of Michigan, Ann Arbor, MI, USA; ${ }^{15}$ Department of Bioethics, National Institutes of Health, Bethesda, MD, USA.

BACKGROUND: Physicians play a key role in mitigating and managing costs in healthcare which are rising. OBJECTIVE: Conduct a cross-sectional survey in 2017 , comparing results to a 2012 survey to understand US physicians' evolving attitudes and strategies concerning healthcare costs.

PARTICIPANTS: Random sample of 1200 US physicians from the AMA Masterfile.

MEASURES: Physician views on responsibility for costs of care, enthusiasm for cost-saving strategies, costconsciousness scale, and practice strategies on addressing cost.

KEY RESULTS: Among 1200 physicians surveyed in 2017, 489 responded (41\%). In 2017, slightly more physicians reported that physicians have a major responsibility for addressing healthcare costs (32\% vs. 27\%, $p=$ 0.03). In 2017, more physicians attributed "major responsibility" for addressing healthcare costs to pharmaceutical companies (68\% vs. 56\%, $p<0.001)$ and hospital and health systems (63\% vs. $56 \% \%, p=0.008)$ in contrast to 2012. Fewer respondents in 2017 attributed major responsibility for addressing costs to trial lawyers (53\% vs. $59 \%, p=0.007)$ and patients ( $42 \%$ vs. $52 \%, p<0.0001)$ as compared to 2012. Physician enthusiasm for patientfocused cost-containment strategies like high deductible health plans and higher co-pays $62 \%$ vs. $42 \%, p<0.0001$ and $62 \%$ vs. $39 \%, p<0.0001$, not enthusiastic, respectively) declined. Physicians reported that when they discussed cost, it resulted in a change in disease management $56 \%$ of the time. Cost-consciousness within

Electronic supplementary material The online version of this article (https://doi.org/10.1007/s11606-020-05807-0) contains supplementary material, which is available to authorized users.

Received October 31, 2019

Accepted March 13, 2020

Published online May 12, 2020 surveyed physicians had not changed meaningfully in 2017 since 2012 (31.7 vs. 31.2). Most physicians continued to agree that decision support tools showing costs would be helpful in their practice (> 70\%). After adjusting for specialty, political affiliation, practice setting, age, and gender, only democratic/independent affiliation remained a significant predictor of cost-consciousness.

CONCLUSIONS AND RELEVANCE: US physicians increasingly attribute responsibility for rising healthcare costs to organizations and express less enthusiasm for strategies that increase patient out-of-pocket cost. Interventions that focus on physician knowledge and communication strategies regarding cost of care may be helpful.

J Gen Intern Med 35(7):1971-8

DOI: $10.1007 / \mathrm{s} 11606-020-05807-0$

() Society of General Internal Medicine 2020

\section{INTRODUCTION}

In 2017 , healthcare costs comprised $18 \%$ of the gross domestic product in the United States (US). ${ }^{1}$ The US spends more on healthcare per capita than world's wealthiest countries. ${ }^{2}$ Physicians' decisions contribute significantly to healthcare expenditures. ${ }^{3}$ Medical societies have recently attempted to guide members to mitigate potential wasteful spending. ${ }^{4}$ Since the signing of the Affordable Care Act (ACA), new payment models and national initiatives have encouraged higher quality and cost-effective delivery. ${ }^{5}$ One of those strategies was the Choosing Wisely Campaign, promoting patient and clinician conversations about tests and interventions. ${ }^{4}$ Results are mixed regarding the familiarity with and impact of Choosing Wisely and related initiatives. ${ }^{6,7}$ 
Understanding physician attitudes, existing strategies, and mindset about their responsibility toward costs could help identify novel strategies for addressing costs in practice and inform policy decisions to control healthcare spending. ${ }^{5,6} \mathrm{In}$ 2012, we surveyed a representative sample of US physicians about their perceptions on stakeholder responsibility for healthcare, enthusiasm for cost-containment strategies, and their cost-consciousness. Physicians reported a modest sense of direct responsibility for healthcare costs, while holding trial lawyers, institutions, insurers, and patients more accountable. ${ }^{8}$ Little is known about how professional attitudes and costsensitive conversational strategies in practice have evolved in the years since the Affordable Care Act was implemented.

In 2017, we surveyed a new representative sample of US physicians about their perceptions of relative stakeholder responsibility for healthcare costs, enthusiasm for various costcontainment strategies, and their cost-consciousness. We compared responses to identical items from the 2012 survey. To better understand how physicians address cost in the clinical encounter, we added items assessing specific strategies deployed in cost conversations with patients.

\section{ETHICAL REVIEW}

The Mayo Clinic Institutional Review Board approved this study.

\section{METHODS}

\section{Study Participants and Data Collection}

We mailed a nine-page paper survey entitled "Physicians, Health Care Costs, and Society" to 1200 US physicians in June 2017, sampling from the American Medical Association Physician Masterfile in an identical fashion to our 2012 survey. ${ }^{8}$ The American Medical Association Masterfile includes more than 1.4 million physicians, residents, medical students, and foreign medical grads. ${ }^{9}$ Physicians represented all specialties. We excluded trainees. We included a $\$ 10$ bill and a stamped return envelope in the first mailing. We sent second and third mailings to non-responders at 30 and 60 days.

\section{Survey Instrument: Dependent Measures}

All survey items were cognitively tested, pilot tested, or used in previous surveys. ${ }^{8}$ Domains identical from the 2012 survey addressed relative responsibility for reducing healthcare costs, enthusiasm for various cost containment strategies, and attitudinal measures comprising a cost-consciousness scale (see Appendix 1 for all survey items). ${ }^{8}$

In the 2017 survey, we added items about strategies to address cost, cost discussions with patients, and the impact of discussions on management used in other surveys. ${ }^{10-13}$ These items, anchored on recollection of a recent costconversation included "Who raised the issue of out-of- pocket medical expenses most recently?", "Did the conversation result in a change in the management plan for the patient?", "How often [physicians] checked out-of-pocket costs when prescribing a new medication?", and their response to the statement "I only find out about a patient's insurance coverage if they have trouble getting something I recommend."

\section{Independent Measures}

We collected measures potentially relevant to cost perceptions including physicians' demographic and practice characteristics gathered from sample variables (age, political affiliation, years in practice, region, specialty, and practice type). In 2017, we measured political party affiliation ("Republican," "Democrat," "Independent," "Other party," and No preference) rather than a previous measure of political ideology on a conservative-liberal spectrum.

\section{Cost-Consciousness Scale}

Cost-consciousness was measured using an 11-item 4-point Likert scale defined as "the extent to which physicians pay attention to and feel an obligation to address healthcare costs in their practice." The score was calculated as the sum of these 11 items, and a higher score indicated a higher level of "costconsciousness" with a possible range from 11 to 44 . $^{8}$

\section{Embedded Experiment Regarding Decision Support Tools and Costs}

In our 2012 survey, most physicians agreed that "decision support tools showing costs would be helpful in my practice," so we wanted to test for potential differences in whose costs - patients', society's, or unspecified - garnered the most support. Therefore, within the 2017 instrument, we developed two additional versions of the item and randomly distributed the versions (versions A-C below) across the sample (400 physicians in each group). "Decision support tools that show [ $\mathrm{A}=$ 'costs' (identical to the 2012 survey), $\mathrm{B}=$ 'total costs to society,') (C= 'patient out-of-pocket costs'] would be helpful in my practice." We hypothesized that physicians would express more agreement with $\mathrm{A}$ or $\mathrm{C}$ compared with $\mathrm{B}$.

\section{Data Analysis}

Survey responses were summarized with frequencies, percentages, means and standard deviations, medians, and ranges. Completers were defined as answering at least $80 \%$ of items. If cost-consciousness items were missing among completers, we calculated the mean of the non-missing items for that respondent re-scaled to the total.

Ordinal survey items (4-point agreement scale, 3-point responsibility scale, and 3-point enthusiasm scale) were compared between 2012 and 2017 with Wilcoxon rank-sum tests. Nominal survey items were compared with chi-squared tests. The cost-consciousness scale scores were compared between 
2012 and 2017 with a two-sample $t$ test. Responses to the 3 versions of the 2017 survey item in the embedded experiment were compared in a pairwise fashion with Wilcoxon rank-sum tests, and the resulting cost-consciousness scale was compared between the three survey versions with pairwise $t$ tests. Linear regression models were used to test associations between costconsciousness scores with physician demographics, enthusiasm for various means of lowering healthcare costs, and perceived responsibility of various entities for costs. $P$ values less than 0.05 were considered statistically significant. All analyses used SAS version 9.4 (SAS Institute Inc., Cary, NC).

\section{RESULTS}

In 2017,489 of the 1200 mailed surveys (41\%) were returned (AAPOR version 2). ${ }^{14}$ In 2012, 2575 of 3897 were returned (66\% response rate). Both 2012 and 2017 had representative samples pulled from the Masterfile. This analysis was restricted to "completer" respondents currently living in the US ("completers": $N=443$ in 2017, $N=2262$ in 2012). As compared to non-completers, completers in 2017 were more likely to be male $(67 \%$ vs. $60 \%, p=0.02)$ and had more years in practice (median 17 vs. 14 years, $p=0.04$ ). There were no other significant differences between completers and non-completers with respect to age, region, or specialty. The 2017 completer and non-completer characteristics are reported in Table 1.

\section{Perceived Stakeholder Responsibility for Controlling Costs}

In general, patterns for attributing responsibility for healthcare costs were similar in 2017 and 2012 (Fig. 1). Overall, 2017 respondents most frequently attributed the highest responsibility to pharmaceutical/device companies (68\% major responsibility), hospitals/health systems (63\% major responsibility), and health insurance companies (62\% major responsibility), followed by trial lawyers, government, patients, physicians, professional societies, and employers. In 2017, more physicians reported that physicians have a major responsibility for addressing healthcare costs (32\% vs. $27 \%, p=0.03)$. Compared with 2012 respondents, 2017 respondents more frequently attributed (major) responsibility to pharmaceutical companies $(68 \%$ vs. $56 \%, p<0.001)$ and hospital/health systems $(63 \%$ vs. $56 \%, p=0.008)$. In contrast, fewer respondents in 2017 attributed major responsibility for costs to trial lawyers $(53 \%$ vs. $59 \%, p=0.007)$ and patients $(42 \%$ vs. $52 \%$, $p<0.0001)$ as compared to 2012 .

\section{Enthusiasm for Various Cost-Containment Strategies}

In 2017, participants reported a high degree of enthusiasm for several cost-containment strategies similar to 2012, including "promoting continuity of care" (98\% very or somewhat enthusiastic), and expanding access to preventative care (89\%
Table 1 Participant and Practice Demographics

\begin{tabular}{|c|c|c|}
\hline \multicolumn{2}{|c|}{$\begin{array}{l}\text { Physicians healthcare costs and society survey } \\
\text { demographics } 2017 \text {, subset to responders with } \\
\geq 80 \% \text { complete questions of interest }\end{array}$} & \multirow[b]{2}{*}{$\begin{array}{l}\text { Non-completers } \\
(\mathbf{N}=757)\end{array}$} \\
\hline & $\begin{array}{l}\text { Completers } \\
(N=443)\end{array}$ & \\
\hline \multicolumn{3}{|l|}{$\overline{\text { Age }}$} \\
\hline$N$ & 443 & 757 \\
\hline \multirow{2}{*}{\multicolumn{3}{|c|}{ Sex }} \\
\hline & & \\
\hline $\mathrm{F}$ & $147(33.2 \%)$ & $301(39.8 \%)$ \\
\hline M & $296(66.8 \%)$ & $456(60.2 \%)$ \\
\hline \multicolumn{3}{|l|}{ Race } \\
\hline Asian & $67(15.1 \%)$ & \\
\hline Black & $15(3.4 \%)$ & \\
\hline Multiple & $8(1.8 \%)$ & \\
\hline Other & $16(3.6 \%)$ & \\
\hline Unknown & $23(5.2 \%)$ & \\
\hline White & $314(70.9 \%)$ & \\
\hline \multicolumn{3}{|l|}{ US regions } \\
\hline Midwest & $175(23.1 \%)$ & $175(23.1 \%)$ \\
\hline Northeast & $158(20.9 \%)$ & $158(20.9 \%)$ \\
\hline South & $254(33.6 \%)$ & $254(33.6 \%)$ \\
\hline West & $170(22.5 \%)$ & $170(22.5 \%)$ \\
\hline \multicolumn{3}{|l|}{ Specialty } \\
\hline Primary care & $175(39.5 \%)$ & $306(40.4 \%)$ \\
\hline Surgery & $99(22.3 \%)$ & $135(17.8 \%)$ \\
\hline $\begin{array}{l}\text { Non-surgical } \\
\text { specialty-procedural }\end{array}$ & $78(17.6 \%)$ & $147(19.4 \%)$ \\
\hline Non-surgical & $74(16.7 \%)$ & $123(16.2 \%)$ \\
\hline specialty - non-procedural & & \\
\hline Non-clinical & $6(1.4 \%)$ & $16(2.1 \%)$ \\
\hline Other & $11(2.5 \%)$ & $30(4.0 \%)$ \\
\hline \multicolumn{3}{|c|}{ Years in practice (years from training completion to survey) } \\
\hline$N$ & 426 & 757 \\
\hline Median (range) & $17.0(0.0-55.0)$ & $14(0.0-56.0)$ \\
\hline \multicolumn{3}{|c|}{ In politics today, do you consider yourself: } \\
\hline Missing & 14 & \\
\hline A Republican & $122(28.4 \%)$ & \\
\hline A Democrat & $140(32.6 \%)$ & \\
\hline An Independent & $128(29.8 \%)$ & \\
\hline Other party & $4(0.9 \%)$ & \\
\hline $\begin{array}{l}\text { No preference/not interested } \\
\text { in politics }\end{array}$ & $35(8.2 \%)$ & \\
\hline \multicolumn{3}{|c|}{ Overall, how satisfied are you with practicing medicine? } \\
\hline Missing & 2 & \\
\hline Very dissatisfied & $30(6.8 \%)$ & \\
\hline Somewhat dissatisfied & $88(20.0 \%)$ & \\
\hline Somewhat satisfied & $178(40.4 \%)$ & \\
\hline Very satisfied & $145(32.9 \%)$ & \\
\hline
\end{tabular}

If blank, data was not available for the non-completers

very or somewhat enthusiastic). However, in 2017, physicians expressed less enthusiasm for interventions requiring greater patient financial stake including high deductible health plans (not enthusiastic $62 \%$ vs. $42 \%, p<0.0001$ ) and higher patient co-pays (not enthusiastic $62 \%$ vs. $39 \%, p<0.0001$ ). In 2017 , fewer physicians expressed enthusiasm that expanding electronic health records, using cost-effectiveness data to determine available treatments, and expanding access to quality and safety data records ( $40 \%$ vs. $28 \%, p=<0.0001 ; 16 \%$ vs. $11 \%$, $p=0.001$; and $11 \%$ vs. $8 \%, p=0.0006$ not enthusiastic, respectively) help address costs. Even more physicians in 2017 reported a lack of enthusiasm for penalizing clinicians for avoidable readmissions ( $68 \%$ vs. $59 \%, p=0.002$, not enthusiastic). In contrast, physicians were more likely to express enthusiasm for "eliminating fee-for-service payment models" (39 vs. $30 \%$ very or somewhat enthusiastic, $p<0.0001$ ). 


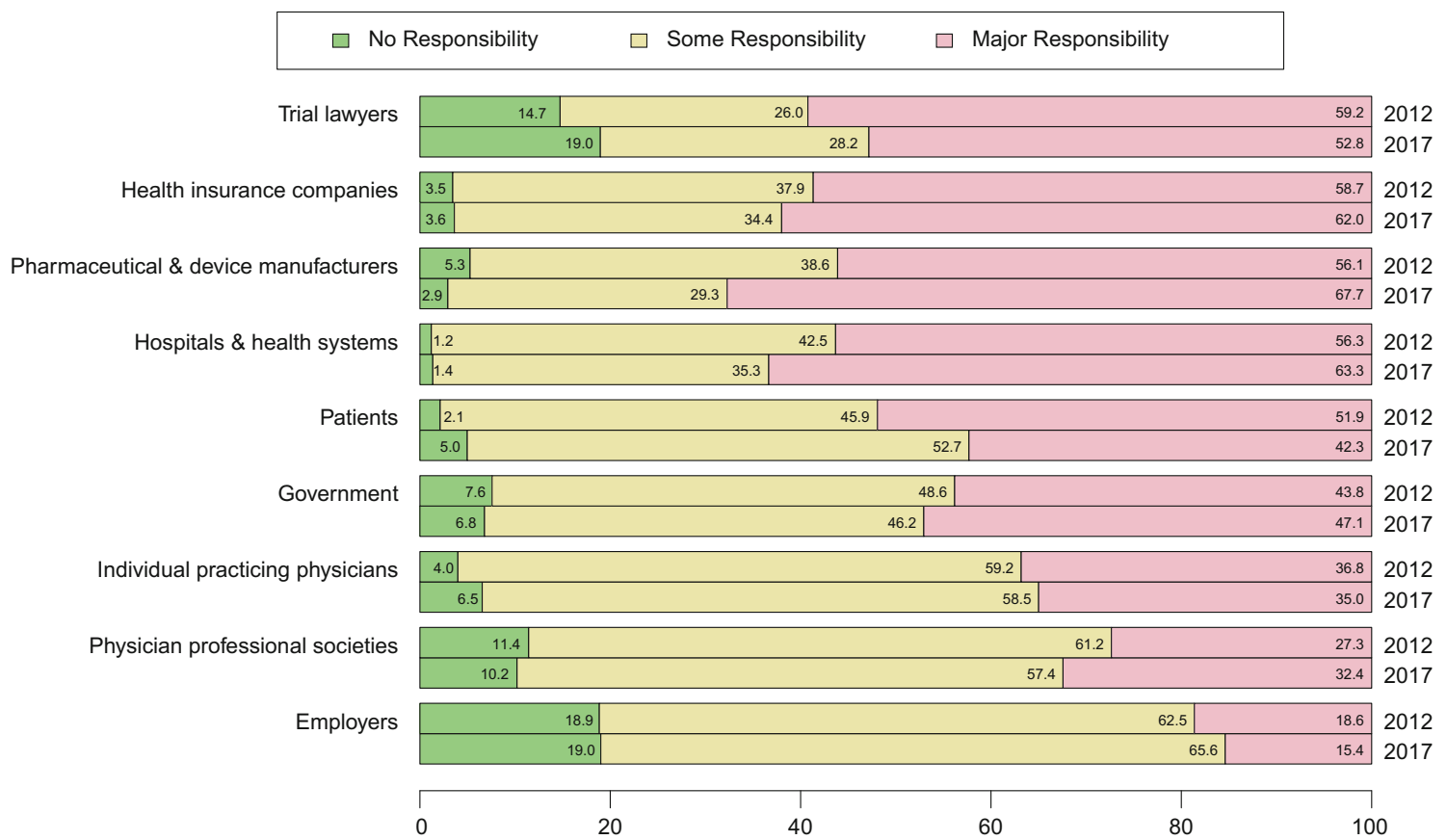

Figure 1 Patterns for attributing responsibility for healthcare costs.

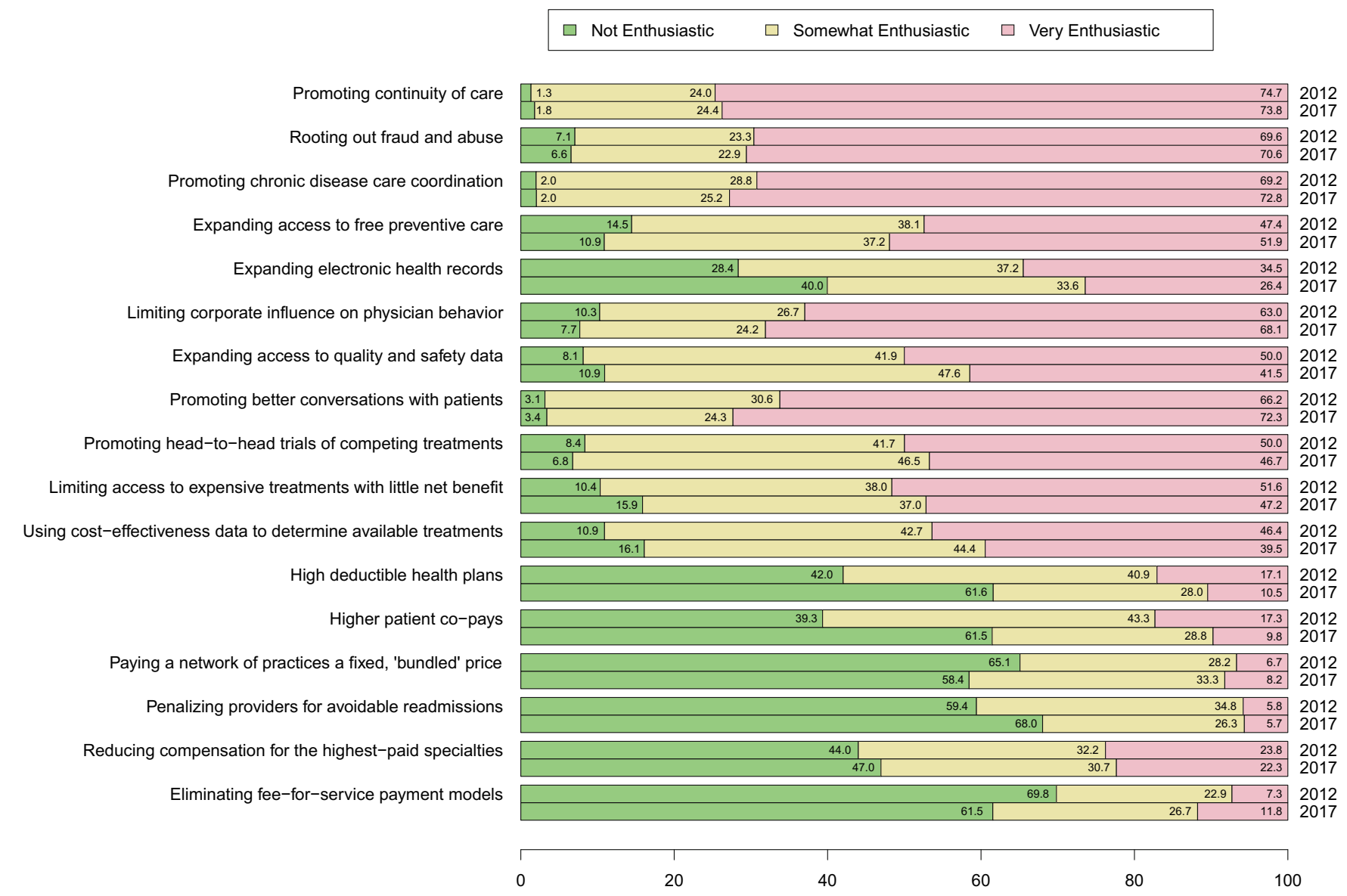

Figure 2 Physician enthusiasm for strategies in 2017 and 2012. 
Figure 2 summarizes physician enthusiasm for strategies in 2017 and 2012.

\section{Cost-Consciousness}

Overall, physician attitudes toward their role in containing costs were similar in 2012 and 2017. Eighty-six percent completed all 11 items of our previously developed costconsciousness scale, $13 \%$ completed 10 items, and $1 \%$ completed 6-9 items. In 2017, the cost-consciousness score derived from the items in Figure 3 was 31.7 (SD = 5.0, range 15-44) similar to the 31.2 (SD 5.2, 11-44) in 2012. More than $80 \%$ of physician respondents in 2017 and 2012 agreed that "physicians should adhere to clinical guidelines that discourage the use of interventions that have a small proven advantage over standard interventions but cost much more", "trying to contain costs is the responsibility of every physician," and "doctors need to take a more prominent role in limiting use of unnecessary testing." In 2017, respondents were more likely to disagree with the statement "it is unfair to ask physicians to be cost-conscious and still keep the welfare of their patients foremost in their minds" (2017 63\% vs. 2012 58\%, $p=0.01)$.

\section{Practice Experience Discussing Cost}

In the 2017 survey only, we included items to understand how specific financial issues are discussed. Thirty-two percent of physicians reported they check potential out-of-pocket costs of prescribed new medications most of the time, and 26\% reported most of the time they discuss out-of-pocket costs of treatments and medications in general. Sixty percent stated they "only find out about a patient's insurance coverage if they have trouble getting something" physicians recommend. When asked about the most recent time out-of-pocket medical expenses were raised, physicians reported patients brought up the topic $46 \%$ of the time and physicians $49 \%$. When out-ofpocket costs were raised, those discussions resulted in a change in management $56 \%$ of the time.

\section{Decision Support Tools That Show Costs}

In 2017, more physicians agreed with the statement that "Decision support tools that show costs would be helpful in my practice" compared to the identical statement in 2012 (version $A$ in 2017$)(79 \%$ vs. $70 \%, p=0.01)$. As hypothesized, the greatest agreement was found with versions $\mathrm{A}$ and $\mathrm{C}$ regarding "costs" or "patient out-of-pocket costs" being helpful to their practice ( $79 \%$ and $75 \%$, respectively, $p=0.73$ ), with version B

$\square$ Strongly disagree $\square$ Moderately disagree $\square$ Moderately agree $\square$ Strongly agree

I am aware of the costs of the tests/treatments I recommend

I try not to think about the cost to the health care system

I should sometimes deny beneficial but costly services because others need them more

Cost to society is important in my decisions to use or not to use an intervention

Physicians should adhere to guidelines discouraging use of costly interventions with small advantage

The cost of a test/med is only important if paying out of pocket

Doctors are too busy to worry about costs of tests and procedures

Trying to contain costs is the responsibility of every physician

There is currently too much emphasis on costs of tests and procedures

Doctors need to take a more prominent role in limiting use of unnecessary tests

It is unfair to ask physicians to be cost-conscious when primarily mindful of patient welfare

I should be solely devoted to my individual patients best interests even if that is expensive

Decision support tools that show costs would be helpful in my practice
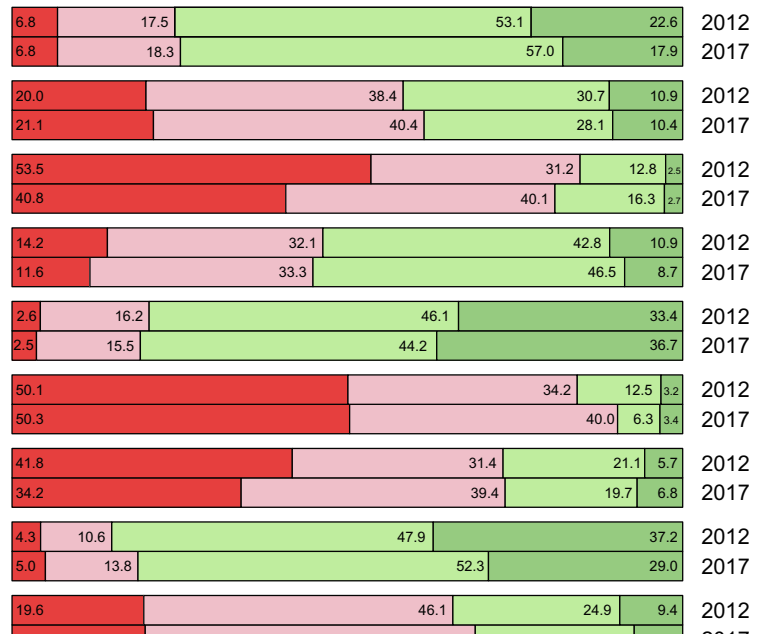

\begin{tabular}{r|r|r|r}
\hline 49.2 & 23.7 & 7.2 & 2017
\end{tabular}
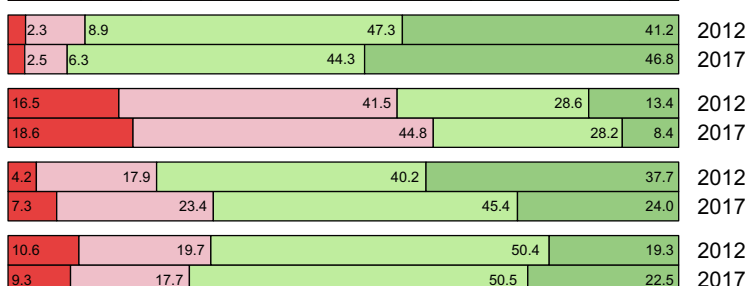

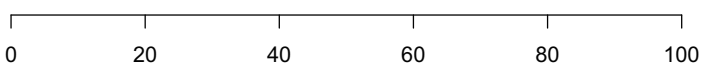

Figure 3 Cost-consciousness score in 2017 and 2012. 
regarding "total costs to society" having the lowest agreement ( $65 \%, p=0.004$ as compared to version A) though a notable majority nonetheless. Agreement with different versions of this item did not seem to differ according to physicians' mean cost-consciousness. The average score for each survey version was 31.6 (version A, "costs"), 32.0 (version B, "total costs to society"), and 31.7 (version C, "patient out-of-pocket costs"), suggesting that randomization worked and the modest effects of the experiment reflect the wording itself and not baseline attitudinal differences.

\section{Associations with Cost-Consciousness}

When we tested for associations between physician characteristics (age, sex, years in practice, region, specialty, and political affiliation) and their overall cost-consciousness in a multivariable model, the only significant association identified was political affiliation. The average cost-consciousness was similar between Independents and Democrats (32.1 vs. 32.7, respectively, $p=0.31$ ), but statistically lower for Republicans (average 30.3) compared to Democrats $(p=0.0002)$ and for Republicans compared to Independents $(p=0.007)$. In models adjusting for political affiliation, several attitudinal measures regarding potential means of lowering healthcare costs were significantly associated with cost-consciousness. Average cost-consciousness was 7.8 points higher for those who felt that individual practicing physicians have "major responsibility to address healthcare costs" as compared to those who felt individual physicians have "no responsibility" $(p<0.0001)$. Additionally, the average cost-consciousness was 5.0 points higher for those who felt that professional societies had "major responsibility" as compared to those who felt they had "no responsibility" ( $p<0.0001)$ (see Appendix Table 2a and b). The [adjusted] average cost-consciousness was 4.7 higher for those who were "very enthusiastic" for using costeffectiveness data to determine available treatments as compared to those who were "not enthusiastic" $(p<0.0001)$. Similarly, the average cost-consciousness was 4.6 higher for those who were "very enthusiastic" for limiting access to expensive treatment with little net benefit as compared to those who were "not enthusiastic" $(p<0.0001)$. Similar differences were noted for other "enthusiasm" items, with those who were most enthusiastic having higher cost-consciousness scores. Enthusiasm for eliminating fee-for-service models was associated with cost-consciousness only among self-identified Democrats, with no significant differences found for Independents or Republicans.

\section{DISCUSSION}

This study examining cost-consciousness, related attitudes, and practice strategies among US physicians shows that their perceived role in addressing healthcare costs has been relatively consistent over a key 5-year period despite changes in policy, guidelines, and costs of care. Yet there is a growing sense that pharmaceutical and insurance companies, healthcare systems, as well as physicians themselves must address healthcare costs. Enthusiasm for electronic health records, high deductible plans, and higher co-pays as costconstraining strategies has waned. Physicians regularly engage patients' cost concerns, though often more reactively rather than proactive.

Physicians are cognizant of the challenges their patients face. One study found that most physicians $(84 \%)$ are aware that patients have forgone medical care in the past year because of costs. ${ }^{15}$ In 2017, there was an $11 \%$ increase in out-ofpocket costs to patients. ${ }^{16}$ Now, one in four adults report difficulty affording prescription medications, ${ }^{15}$ which then fosters non-adherence and poorer clinical outcomes especially among those of low socioeconomic status. ${ }^{17}$ Though we cannot posit direct causal relationships, the observed shifts in attributing greater responsibility toward pharmaceutical and insurance companies, healthcare systems and their lack of enthusiasm for strategies that transfer more cost-sharing burdens to patients (high deductibles, and co-payments) may reflect practice experience and these cost trends in recent years. ${ }^{18,} 19$ Physicians are increasingly aware of the added financial duress patients face and likely reflect the decline in enthusiasm for patient-focused cost-containment strategies.

One could ponder how physicians' view on healthcare cost-controlling strategies aligns with what has shown to work, particularly the high enthusiasm for "win-win" approaches? In our study, across 2012 and 2017, physicians sustained high enthusiasm for promoting continuity of care and chronic disease coordination. These strategies may have at least modest cost reduction that is better for patients, and society as a whole. ${ }^{20}$ Studies have shown that preventable causes of death such as tobacco smoking, poor diet, physical activity, and excessive alcohol intake account for $40 \%$ of total yearly mortality rates. ${ }^{21}$ Furthermore, the US Preventative Services Task Force identified that measures such as colorectal screening, influenza vaccinations, and smoking cessation counseling reduce mortality at a low or at a cost savings. ${ }^{22}$ These views may be socially desirable for physicians to agree with since they are congruent with traditional ethics of medicine.

Cost discussions frequently appear to change management, when they occur. This finding mirrors that of Zafar et al., who found that among patients who discuss out-of-pocket costs with clinicians, $57 \%$ reported paying less. ${ }^{23}$ Other studies also document cost of care as a relevant topic for clinical visits. ${ }^{24-}$ ${ }^{26}$ However, the actual frequency of discussing costs varies widely $19-44 \% .^{27-30}$ Physicians may value cost discussions but not routinely and proactively conduct them. A survey of 333 oncologists found that lack of knowledge on content $(58 \%)$ and time $(44 \%)$ were the most common reasons to avoid discussing cost of care. ${ }^{31}$ Others note uncertainty about available resources as a constraint. ${ }^{32}$ Together, these suggest physicians may need more knowledge, time, and resources to comfortably engage with their patients on this topic. 
Physicians seem to welcome decision support tools that show costs, especially if they showed out-of-pocket costs for patients. This finding coheres with data showing relative patient indifference toward insurance company and societal impact, favoring out-of-pocket costs instead. ${ }^{33,}{ }^{34}$ Among 17 studies (12 clinical, 5 survey) that displayed charge information ordering and prescribing behavior changed. ${ }^{35}$ Although there is enthusiasm for decision support tools, how best to incorporate into workflows remains to be determined. While information about societal costs was valuable to fewer physicians than patient's costs, our data suggest anything is better than nothing from the physician perspective.

The last 5 years have seen substantial changes and uncertainty in the direction of healthcare. Amidst these changes, overall cost-consciousness among physicians has not changed, yet a growing minority of physicians see themselves a key responsible group in addressing healthcare costs among other players. However, there may be greater endorsement of physicians' seeking to constrain costs while upholding patient welfare at the same time. This increased willingness toward being dual advocates - both for individual patients and for greater societal resource stewardship - can be challenging, but may be inescapable in contemporary healthcare. Our finding that physician cost-consciousness was associated with political affiliation mirror-related reports on physician opinions about the Affordable Care Act. ${ }^{36,37}$

\section{LIMITATIONS}

This study utilized the American Medical Association Masterfile, a comprehensive listing of nearly all US physicians, in 2012 and 2017, sampled different cohorts. Differences in sample demographics may reflect broader practice and demographic changes for physicians generally that shape our inferences. The 2017 sample size was smaller, had a lower response rate, and may be less representative of the population given. Not all items were validated but all were cognitively tested with practicing clinicians and checked with multiple experts within survey research. Lastly, the change in the wording to party identification from political ideology (liberal/moderate/conservative) between the 2017 and 2012 surveys limited our ability to compare the role of political affiliation across time.

\section{CONCLUSION}

Within a rapidly changing healthcare environment, physicians' cost-consciousness has not changed, yet they seem increasingly convinced that pharmaceutical companies and insurance providers as well as themselves are key in addressing healthcare costs - responsibilities that cannot be passed off onto patients. In recent years, physicians have been navigating the delicate balance of patient-centered care and broader societal healthcare costs more frequently. While physicians are skilled in discussing costs to a degree, interventions that facilitate education and information on costs as well as practice-based communication strategies could help curb costs and help alleviate the burden that millions of patients and society as a whole face.

Corresponding Author: Rahma Warsame, MD; Mayo Clinic Robert D. and Patricia E. Kern Center for the Science of Health Care Delivery, Mayo Clinic, Rochester, MN, USA (e-mail: warsame.rahma@mayo. edu).

Funding Information This study was supported by the Small Grants Program of the Mayo Clinic's Division of General Internal Medicine and by the National Center for Advancing Translational Sciences (Grant No. UL1 TR002377). Dr. Thorsteinsdottir was on a K grant from the National Institute on Ageing.

\section{Compliance with Ethical Standards:}

The Mayo Clinic Institutional Review Board approved this study.

Conflict of Interest: The authors declare that they do not have a conflict of interest.

\section{REFERENCES}

1. Sisko AM, Keehan SP, Poisal JA, Cuckler GA, Smith SD, Madison AJ, et al. National Health Expenditure Projections, 2018-27: Economic And Demographic Trends Drive Spending And Enrollment Growth. Health Aff (Project Hope) 2019;38(3):491-501.

2. Sawyer BaCCKFF. How does health spending in the U.S. compare to other countries? 2018 Available from: https://www.healthsystemtracker. org/chart-collection/health-spending-u-s-compare-countries/\#itemstart. Accessed 20 July 2019

3. Institute PLHR. The Price of Excess: Identifying Waste in Healthcare Spending: PricewaterhouseCoopers' Health Research Institute. 2008.

4. Cassel CK, Guest JA. Choosing wisely: helping physicians and patients make smart decisions about their care. Jama. 2012;307(17):1801-2.

5. Borelli MC, Bujanda M, Maier K. The Affordable Care Act Insurance Reforms: Where Are We Now, and What's Next? Clin Diabetes 2016;34(1):58-64.

6. Borelli MC, Bujanda M, Maier $\mathbf{K}$. The Affordable Care Act Insurance Reforms: Where Are We Now, and What's Next?. Clin Diabetes. 2016;34(1):58-64. https://doi.org/10.2337/diaclin.34.1.58

7. Kerr EA, Kullgren JT, Saini SD. Choosing Wisely: How To Fulfill The Promise In The Next 5 Years. Health Aff (Project Hope) 2017;36(11):2012-8.

8. Tilburt JC, Wynia MK, Sheeler RD, Thorsteinsdottir B, James KM, Egginton JS, et al. Views of US physicians about controlling health care costs. Jama. 2013;310(4):380-8.

9. Association AM. Available from: https://www.ama-assn.org/practicemanagement/masterfile/ama-physician-masterfile. Accessed 1 Feb 2020

10. AMA (Data Resources) AMA Physician Masterfile. https://www.amaassn.org/practice-management/masterfile/amaphysician-masterfile. Accessed 1 Feb 2020.

11. Antiel RM, James KM, Egginton JS, Sheeler RD, Liebow M, Goold SD, et al. Specialty, political affiliation, and perceived social responsibility are associated with U.S. physician reactions to health care reform legislation. J Gen Intern Med 2014;29(2):399-403.

12. Antiel RM, James KM, Egginton JS, et al. Specialty, political affiliation, and perceived social responsibility are associated with U.S. physician reactions to health care reform legislation. J Gen Intern Med. 2014;29(2):399-403. https://doi.org/10.1007/s11606-013-2718-4

13. Healthy Michigan Plan. Michigan Department of Health and Human Services. 2017. http://www.michigan.gov/mdhhs/0,5885,7-339-71547 2943_66797-,00.html. Accessed 20 July 2019.

14. American Association for Public Opinion Research. Standard Definitions: Final Dispositions of Case Codes and Outcome Rates for Surveys. 7th ed.Lenexa, KS: AAPOR; 2011 
15. Kaiser Family Foundation. Health Tracking Poll 2019. Available from: https://www.kff.org/health-reform/poll-finding/kff-health-tracking-pollfebruary-2019-prescription-drugs/. Accessed 20 July 2019

16. Helathcare T. Patient Payment Responsibility Increases 11\% in 2017 2017 Available from: https://newsroom.transunion.com/patient-payment-responsibility-increases-11-in-2017/. Accessed 2 Feb 2020

17. Choudhry NK, Saya UY, Shrank WH, Greenberg JO, Melia C, Bilodeau A, et al. Cost-related medication underuse: prevalence among hospitalized managed care patients. J Hosp Med 2012;7(2):104-9.

18. Alpern JD, Stauffer WM, Kesselheim AS. High-cost generic drugsimplications for patients and policymakers. N Engl J Med 2014;371(20): 1859-62.

19. Schumock GT, Li EC, Suda KJ, Wiest MD, Stubbings J, Matusiak LM, et al. National trends in prescription drug expenditures and projections for 2016. Am J Health Syst Pharm 2016;73(14): 1058-75.

20. Russel LB. Preventio's potnential for slowing the growth of Medical Spending. Washington D.C.: National Coaliatio on Healthcare; 2007.

21. Mokdad AH, Marks JS, Stroup DF, Gerberding JL. Actual causes of death in the United States, 2000. Jama. 2004;291(10):1238-45.

22. Maciosek MV, Coffield AB, Edwards NM, Flottemesch TJ, Goodman MJ, Solberg LI. Priorities among effective clinical preventive services: results of a systematic review and analysis. Am J Prev Med 2006;31(1):52-61.

23. Zafar SY, Chino F, Ubel PA, Rushing C, Samsa G, Altomare I, et al. The utility of cost discussions between patients with cancer and oncologists. Am J Manag Care 2015;21(9):607-15.

24. Alexander GC, Casalino LP, Meltzer DO. Patient-physician communication about out-of-pocket costs. Jama. 2003;290(7):953-8.

25. Pham HH, Alexander GC, O'Malley AS. Physician consideration of patients' out-of-pocket costs in making common clinical decisions. Arch Intern Med 2007;167(7):663-8.

26. Richman IB, Brodie M. A National study of burdensome health care costs among non-elderly Americans. BMC Health Serv Res 2014;14:435.

27. Patel MR, Shah KS, Shallcross ML. A qualitative study of physician perspectives of cost-related communication and patients' financial burden with managing chronic disease. BMC Health Serv Res 2015; 15:518.
28. Bestvina CM, Zullig LL, Rushing C, Chino F, Samsa GP, Altomare I, et al. Patient-oncologist cost communication, financial distress, and medication adherence. J Oncol Pract 2014;10(3):162-7.

29. Warsame R, Kennedy CC, Kumbamu A, Branda M, Fernandez C, Kimball B et al. Conversations About Financial Issues in Routine Oncology Practices: A Multicenter Study. J Oncol Prac 2019;15(8):e690e703. https://doi.org/10.1200/JOP.18.00618

30. Schmittdiel JA, Steers N, Duru OK, Ettner SL, Brown AF, Fung V, et al. Patient-provider communication regarding drug costs in Medicare Part D beneficiaries with diabetes: a TRIAD Study. BMC Health Serv Res 2010;10:164.

31. Altomare I, Irwin B, Zafar SY, Houck K, Maloney B, Greenup R, et al. Physician Experience and Attitudes Toward Addressing the Cost of Cancer Care. J Oncol Pract 2016;12(3):e281-8, 47-8.

32. Alexander GC, Casalino LP, Tseng CW, McFadden D, Meltzer Do. Barriers to patient-physician communication about out-of-pocket costs. J Gen Intern Med 2004;19(8):856-60.

33. Danis M, Sommers R, Logan J, Weidmer B, Chen S, Goold S, et al. Exploring public attitudes towards approaches to discussing costs in the clinical encounter. J Gen Intern Med 2014;29(1):223-9.

34. Sommers R, Goold SD, McGlynn EA, Pearson SD, Danis M. Focus groups highlight that many patients object to clinicians' focusing on costs. Health Aff (Project Hope) 2013;32(2):338-46.

35. Goetz C, Rotman SR, Hartoularos G, Bishop TF. The effect of charge display on cost of care and physician practice behaviors: a systematic review. J Gen Intern Med 2015;30(6):835-42.

36. Riordan L, Warsame R, Jenkins S, Lackore K, Paycna J, Antiel R, et. al. U.S. Physician Reactions to ACA Implementation, 2012-2017. Health Affairs September 2019;238(9):1530-1536.

37. Jacobs LR, Mettler S. Liking Health Reform But Turned Off By Toxic Politics. Health Aff (Project Hope) 2016;35(5):915-22.

Publisher's Note Springer Nature remains neutral with regard to jurisdictional claims in published maps and institutional affiliations. 